\title{
Los estudios geológicos en las conferencias científicas de la Escuela Normal para Profesoras de la ciudad de México, 1891-1902
}

Geology Lectures at the Women's teacher training College in Mexico City, 1891-1902

\author{
Rodrigo Vega y Ortega \\ Facultad de Filosofía y Letras-UNAM \\ rodrigo.vegayortega@hotmail.com
}

\begin{abstract}
Resumen
Entre 1891 y 1902, algunas alumnas de la Escuela Normal para Profesoras de la ciudad de México expusieron ocho conferencias geológicas como parte de los ejercicios literarios anuales. En éstas, las estudiantes desarrollaron algunos temas bajo la perspectiva positiva y romántica de la ciencia. El análisis de dichas conferencias, bajo la perspectiva de la historia social, permite comprender la incursión de las mujeres en una disciplina hasta entonces reservada a los varones para que propagaran el conocimiento geológico en la escuela primaria mediante un lenguaje ameno y sencillo. El conjunto de las conferencias fungió como un ensayo docente, ya que las estudiantes debían elaborar un escrito y presentarlo públicamente, tal cual lo harían ante un grupo de niños a lo largo de su vida.
\end{abstract}

Palabras clave: mujer, magisterio, geología, ciencia, educación.

\footnotetext{
${ }^{1}$ Esta investigación forma parte del proyecto PAPIIT (in 301113) "La Geografía y las ciencias naturales en algunas ciudades y regiones mexicanas, 1787-1940". Responsable: Dra. Luz Fernanda Azuela. También es parte de una investigación amplia titulada "La incursión de las mujeres mexicanas en la ciencia a través de las conferencias científicas de la Escuela Normal para Profesoras de la ciudad de México, 1891-1905", como parte del proyecto PIFFYl (2014-009): "Historia socio-cultural de la ciencia y la tecnología de México, 1821-1911". Responsable Rodrigo Vega y Ortega, Facultad de Filosofía y Letras-UNAM.
} 
Abstract

Between 1891 and 1902, a number of students from the Mexico City Women's Teacher Training College (Escuela Normal para Profesoras) held a series of eight lectures on geology as part of their annual literany exercises. During the lectures, the students discussed various topics from a romantic and positivist perspective on science. The analysis of these practices from the perspective of social history enables us to understand how women came to involve themselves in a discipline which, up to then, had been the preserve of men in order to spread knowledge of geology in primary schools through language that was both simple and accessible. This group of lectures also served as a training ground for teachers, as the trainees had to both write a presentation and perform it in public, just as they would for groups of students during the rest of their professional lives.

Keywords: Female; Teaching; Geology; Science; Education.

\section{Introducción}

Los estudios históricos sobre las mujeres mexicanas han cobrado auge en las últimas décadas mediante el análisis de una amplia gama de fuentes y bajo distintas perspectivas. Entre los temas de mayor interés se encuentra la irrupción de éstas en las escuelas profesionales de carácter científico en algunas ciudades, sobre todo la ciudad de México, como el caso de Matilde Montoya (Medicina), Esther Luque (Farmacia) y Eulalia Ruiz Sandoval (Enfermería), así como las investigaciones sobre las numerosas jovencitas que egresaron de las escuelas normalistas. Sin embargo, aún son escasos los estudios acerca de la instrucción científica que se impartió a las alumnas de la Escuela Normal para Profesoras de la Ciudad de México (ENPCM). Una vía para caracterizar tal instrucción se encuentra en las conferencias públicas que éstas presentaron entre 1891 y 1904 en el salón de actos de la ENPCM. Entre la gama de ciencias que fueron tema de las conferencias destacó la geología, unida a la Geografía y la Historia Natural, en cuatro temas: el examen de la composición y origen del planeta Tierra; el escrutinio de los fenómenos sísmicos; la exposición de las bellezas geológicas, y el estudio de los minerales. Este interés estuvo acorde con el auge de los temas geológicos al final del siglo XIX entre los ingenieros y naturalistas de México, pues estaban relacionados con la explotación de los recursos del subsuelo.

Las 131 conferencias presentadas por algunas alumnas normalistas fueron parte de trece ejercicios literarios anuales que abarcaron las siguientes disciplinas de acuerdo con el número de conferencias: medicina (26), historia natural (21), geografía (19), física (17), meteorología (13), geología (8), generalidades de la ciencia (6), astronomía (6), tecnología (5), química (4), educación (4), psicología (1) y matemáticas (1). El ámbito geológico ocu- 
pó el sexto lugar, lo que muestra el terreno que gozó en la instrucción científica femenina. Es de suponer que las jovencitas aprendían en las cátedras a identificar las características mineralógicas del planeta, los accidentes de la superficie de la Tierra, la diversidad de rocas que componían su centro y superficie, las particularidades de las eras geológicas y las explicaciones sobre la sismicidad.

El objetivo de la investigación es entender la irrupción de las estudiantes normalistas en la práctica geológica a través de las ocho conferencias en tanto aspirantes a profesoras de instrucción primaria, pues la mayoría de ellas se desempeñó como docente durante varias décadas y es de suponer que transmitieron a los infantes la pasión por la geología. Este estudio da luz sobre la intervención de las mujeres mexicanas en la práctica de dicha ciencia, desde la docencia y la popularización.

La metodología se basa en el análisis de las ocho conferencias geológicas desde la perspectiva de la historia social de la ciencia que da pie a valorar a las pupilas como parte del desarrollo de la instrucción científica mexicana de finales del siglo XIX, pues aunque esta perspectiva en el terreno educativo ha sido fecunda por varios años, en el campo de la ciencia aún se cuenta con pocos estudios. Las alumnas fueron actores de la geología "en su manera de aprehender, comprender, apropiarse e interpretar las actividades y producciones de la ciencia", aunque su participación no es equiparable a la de ingenieros y naturalistas (Vaccarezza, 2009: 76). Esta perspectiva propicia la inclusión de grupos sociales que la historiografía tradicional de la ciencia mexicana no ha considerado como actores de la cultura científica de finales del siglo XIX, en este caso las jóvenes aspirantes a profesoras de instrucción primaria, pues desde 1891, las ciencias se integraron en la formación de las futuras docentes de la ciudad de México como parte del proceso de profesionalización y como iniciación de los niños en la moderna cultura científica (Vega y Ortega, 2011: 247-266). En efecto, la historia social "pone en tela de juicio los conceptos tradicionales sobre el pasado" de la ciencia de nuestro país (Tanck, 1976: 43).

La perspectiva social ha permitido vislumbrar que las profesoras egresadas de la ENPCM, como de otras instituciones similares de México, "compartían aquella idea de que la escuela pública tenía una función política al otorgarle la misión de promover la cohesión nacional, la moralización de la sociedad y el mantenimiento del orden social" (Lionetti y Civera, 2010: 17). Esta misión tuvo como uno de sus pilares el saber científico, que se erigía como un terreno ajeno a la diversidad social, ideológica, religiosa, étnica y regional. De esta manera, se irradiaría el mismo conocimiento a todos los infantes que asistieran a la escuela primaria.

Las conferencias no buscaban la innovación en las ciencias, pues como se expuso en la "Introducción" a los ejercicios literarios de 1894, el público "no [encontraría] datos nuevos o aseveraciones propias, ni podía esperarse esto de jóvenes que [empezaban] a dar los primeros pasos en el seno de la ciencia" ("Introducción", 1895: 3). Estas palabras revelan que 
las conferencias permitían a las alumnas adentrarse en la práctica geológica que hasta 1890 estuvo reservada a los hombres mexicanos, sin que por ello se esperara que innovaran en el ámbito científico, ni práctico ni teórico.

Los discursos geológicos que expusieron las alumnas normalistas se basaron en los temas impartidos en las cátedras de historia natural (segundo año), cosmografía y geografía de México (segundo año) y geografía general (tercer año). En las tres cátedras convivían las vertientes explicativas de carácter romántico y positivo empleadas en la instrucción de primeras letras, en las cuales las profesoras normalistas debían estar al tanto. La primera exaltaba las bellas peculiaridades y la singularidad de los fenómenos geológicos del territorio patrio y la segunda aportaba datos y explicaciones para comprender el origen de ambos tópicos. Esta unión se encaminaba a crear una representación científica del territorio acorde con la tierna edad de los pupilos.

El conjunto de las conferencias geológicas que impartieron las alumnas normalistas fungió como un ensayo docente, ya que éstas debían elaborar un escrito y presentarlo públicamente, tal cual lo harían ante un grupo de infantes a lo largo de su vida. Los temas expuestos en las conferencias fueron una vía recurrente para instruir a los menores de edad en términos científicos, pues no se requería que las profesoras emprendieran investigaciones originales, ya que entre 1891 y 1904 éstas se reservaban a los varones. Las futuras profesoras transmitirían el conocimiento generado por los naturalistas e ingenieros mexicanos y extranjeros mediante un lenguaje ameno y sencillo, similar a las conferencias anuales de la Escuela.

Las discípulas de la ENPCM citaron en varias ocasiones a conocidos científicos de la talla de Isaac Newton (1642-1727), Nevil Maskelyne (1732-1811), Henry Cavendish (1731-1810), Pierre-Simon Laplace (1749-1827), Francis Baily (1774-1844), Ferdinand Reich (1799-1882), Urbain Le Verrier (1811-1877), y algunos otros, gracias a las obras consultadas en la biblioteca de la institución. Entre los científicos mexicanos, las conferencistas mencionaron las obra de Eugenio Landesio (1810-1879), Mariano Bárcena (1842-1899) y Antonio del Castillo (1820-1895), como parte de la validación educativa de la ciencia nacional de finales de la centuria.

Cabe señalar que los temas geológicos incluidos en los libros de geografía y de "lecciones de cosas" empleados en la instrucción primaria se vincularon con los contenidos de las cátedras señaladas que cursaban las estudiantes de la ENPCM. De esta manera, las alumnas se adentraban a la geología para luego exponer lo aprendido a los infantes (Aguirre, 2010: 268). Esto sucedió con otros saberes humanísticos, artísticos y científicos. 


\section{La práctica de la geología en la ciudad de México, 1890-1905}

La geología mexicana al final del siglo XIX se desarrolló en varios espacios científicos repartidos en el país, sobre todo, en las escuelas de instrucción superior. En el caso de la ciudad de México, los ingenieros, geógrafos y naturalistas concentraron la instrucción de esta ciencia en la Escuela Nacional de Ingenieros, mientras que en el terreno asociativo se afincó en la Sociedad Mexicana de Geografía y Estadística (desde 1833), la Sociedad Mexicana de Historia Natural (1868-1914), la Asociación de Ingenieros y Arquitectos de México (18681946) y la Sociedad Científica "Antonio Alzate" (1884-1930). En cuanto a la exhibición de los objetos geológicos en las colecciones públicas, resaltó el Museo Nacional (1825-1909) y la Secretaría de Fomento en el medio gubernamental al patrocinar las comisiones Geográfico Exploradora (1877-1914) y Geológica Nacional (1888-1890). Por último, en la vertiente institucional, esta ciencia se concentró en el Instituto Geológico Nacional (1891), cuya fundación coincidió con la ENPCM (Azuela y Vega y Ortega, 2011: 51-90). También hubo actividades geológicas de tinte económico en las empresas ferrocarrileras, de puentes y caminos, y en la explotación de recursos del subsuelo (minerales y petróleo). Todos esos espacios fueron masculinos y convivieron con el conocimiento geológico que se enseñaba en las cátedras de geología, geografía e historia natural destinadas a formar a las futuras profesoras normalistas.

En 1881 la geología dio los primeros pasos hacia la consolidación como disciplina independiente de la geografía y la historia natural cuando en la Escuela Nacional de Ingenieros se fundó la cátedra de mineralogía, geología y paleontología que favoreció el escrutinio geológico de la República mexicana. Esto se llevó a cabo por los catedráticos, egresados y estudiantes de la ENI, pues "requirió del concurso de los técnicos, peritos y expertos, así como de la organización de establecimientos adecuados para emprender las labores de exploración y reconocimiento" de la diversidad mineral, la estructura litológica y la gama de fósiles del territorio mexicano (Azuela, 2011: 74). A partir de entonces, fue común que los ingenieros recibieran "encargos y comisiones del gobierno para efectuar estudios geológicos y mineralógicos", ya fuera como parte de las mencionadas agrupaciones, escuelas, comisiones e instituciones (Azuela, 1994: 83). No obstante, tal separación teórica y práctica de la geología requirió de un largo proceso en el resto de instancias educativas, como la ENPCM, en las cuales esta ciencia fue parte de los planes de estudios de las cátedras geográficas y naturalistas (Vega y Ortega, 2013: 56-79).

En el proceso de demarcación de la geología mexicana, las profesoras normalistas de la ciudad de México fueron fundamentales al participar como propagadoras de las explicaciones de las peculiaridades y fenómenos geológicos entre los pupilos de la escuela primaria o 
la divulgación en manuales, folletos y revistas destinados a un público amplio. Esto fue posible gracias a los conocimientos que las estudiantes de la ENPCM recibieron a través de las cátedras señaladas.

\section{La Escuela Normal para Profesoras de la Ciudad de México, 1890-1904}

La ley de 2 de diciembre de 1867 fundó el primer establecimiento de instrucción pública femenina para las jovencitas interesadas en ampliar los conocimientos adquiridos en las escuelas de primeras letras. Éste fue la Escuela Secundaria para Personas del Sexo Femenino (ESPSF) inaugurada en 1869. La ESPSF incluyó en el plan de estudios algunas asignaturas científicas de corte positivo, como rudimentos de álgebra y geometría, cosmografía y geografía física, medicina, nociones de horticultura y jardinería, junto con un "grupo de materias relacionadas directamente con las tradicionales funciones femeninas [...] que les permitiría cumplir con las tareas domésticas" (Alvarado, 2008: 109). La ley estuvo elaborada por intelectuales liberales y positivistas que creían que "educar a las mujeres era un punto central del programa reformador" de la sociedad mexicana. Resultaba indispensable "abrir el abanico disciplinario lo suficiente como para formar madres capaces y republicanas leales a las nuevas ideas y no a los intereses del clero" (Alvarado, 1999: 418). Para alcanzar tales anhelos, las ciencias tendrían un lugar esencial, pues la ley de 1867 dio pie a la incursión de las mujeres en profesiones como el magisterio de primeras letras, enfermería y farmacia, valoradas como "actividades públicas y remuneradas" aptas para la "personalidad" femenina (López, 2003: 37). Las jóvenes interesadas en tales profesiones debían cursar estudios científicos en la ESPSF a la par que los varones de la Escuela Nacional Preparatoria.

La ESPSF estuvo en funciones entre el julio de 1869 y febrero de 1890 cuando se transformó en la ENPCM. La nueva institución educativa requirió de arreglos en la planta de catedráticos, "reorganizar los cursos según los cánones pedagógicos y comprar los instrumentos científicos faltantes" (Alvarado, 2008: 113). Entre las nuevas materias estuvo historia natural, aritmética y álgebra, y geometría.

A partir de 1890 las mujeres capitalinas dieron el primer paso para incursionar de forma profesional en las escuelas de niños y al finalizar la centuria se tradujo en una mayoría femenina en el medio docente (García Alcaraz, 2008: 140). Sin embargo, entre 1891 y 1905, los hombres fueron los titulares de las cátedras científicas, mientras que las mujeres "impartían materias básicas vinculadas a las tareas femeninas como escritura y caligrafía, gramática, música y canto, labores manuales y cocina" (Galván, 2008: 184). Esta distinción en la planta docente estuvo acorde con las expectativas de las conferencias científicas de la ENPCM al 
enfatizar que las jovencitas requerían de la guía masculina en la iniciación científica para ejercer las actividades de docencia y de divulgación.

\section{Los ejercicios literarios, 1891-1904}

Las conferencias científicas de la ENPCM tuvieron como origen el artículo 88 del capítulo XIV "De los ejercicios literarios" del reglamento emitido en 1890. Éste señalaba que cada año se llevaría a cabo un evento público en que las alumnas destacadas de cada asignatura presentarían un discurso. Para redactar el reglamento de los ejercicios literarios, la directora Rafaela Suárez designó una comisión formada por los profesores Manuel Aristi, Manuel Flores y Francisco Gómez Flores que el 20 de noviembre dieron a conocer el "Reglamento para los ejercicios literarios" ("Art. 88 del reglamento: ejercicios literarios", 1891: 3). En éste se estableció que las conferencias se presentarían los sábados de junio y julio a las seis de la tarde. En el reglamento se determinaba que el profesor designaría a las discípulas que leerían una conferencia entre 20 y 45 minutos sobre algún tema de la cátedra científica, mismas que gozaron de un lugar destacado en las actividades de la Escuela, pues preparaban a las futuras profesoras en la modernidad que inculcarían a los infantes.

La buena acogida de los ejercicios literarios fue tan grande que la Secretaría de Fomento publicó las conferencias como un ejemplo de la confianza del gobierno de Porfirio Díaz hacia la instrucción científica ofrecida en la ENPCM. Los trece volúmenes que reunieron las conferencias presentadas entre 1891 y 1905 incluyeron una introducción que reseña el evento anual. Por ejemplo, la "Introducción" sobre las conferencias de 1896 insistía en que éstas sólo demostraban la comprensión de las alumnas sobre "las doctrinas conocidas que como maestras [tendrían] que enseñar más tarde" en la escuela primaria. "Esto [bastaba] por sí solo para satisfacer las exigencias de una escuela nacional cuya misión no [era] formar las creadoras y descubridoras de la verdad científica, sino tan sólo propagadoras y vulgarizadoras de la verdad ya conquistada por los sabios" ("Introducción", 1897: 4). Es claro que el propósito de los ejercicios literarios fue profesionalizar a las pupilas en el rubro de las ciencias, pues al egresar se encargarían de la educación laica, positiva y "verdadera" de las nuevas generaciones de mexicanos. En este sentido, el propósito de la ENPCM no era el egreso de mujeres científicas equiparables a los estudiantes de las escuelas de instrucción superior de varones, ya que éstos eran concebidos como los únicos "creadores" del conocimiento científico.

En la introducción de las conferencias presentadas en 1899 se afirmó que año con año se demostraba "que no [carecían] de utilidad las conferencias en que algunas de las alumnas más aprovechadas de la Escuela Normal [procuraban] hacer patentes sus conocimientos 
científicos y sus facultades oratorias" como un testimonio de la inteligencia de las jóvenes mexicanas ("Conferencias científicas", 1901: 3-6). Tanto hombres como mujeres mostraban la misma capacidad para cursar cátedras científicas de estudios profesionales, pero la diferencia radicaba en la utilidad de éstas en el futuro laboral de unos y otras. En efecto, a las jovencitas se les preparaba para transmitir la ciencia en la instrucción primaria, mientras que a los varones se les aleccionaba para profundizar en los conocimientos científicos o desempeñarse como profesionistas (médicos, ingenieros, farmacéuticos, geógrafos o veterinarios).

Las palabras introductorias también expresaban que los volúmenes recopilatorios de las conferencias servirían como estímulo a las nuevas generaciones de alumnas de la ENPC, es decir, como evidencia de la inteligencia femenina y facilitaría "a los historiadores el estudio de la fisonomía intelectual de México durante su actual periodo evolutivo [...] que [contenía] no solamente el frío relato de lo aprendido, sino juicios y apreciaciones personalísimos" de cada una de las conferencistas. De esta manera, la "Introducción" revela el reconocimiento de los ejercicios literarios como un hito en la historia educativa, intelectual y científica de México a manera de expresión de los primeros pasos de varias jovencitas en el terreno de las ciencias.

A tono con la "Introducción", en 1901 la alumna Angelina Zamora presentó la conferencia titulada "Amor a la ciencia". En ésta se alabó la presidencia de Porfirio Díaz como un régimen de paz y estabilidad social tras cruentos "años que pasó, en destructoras guerras, mi patria adorada", sin poder concretar el anhelado "progreso". A partir de 1876 proliferaron los "héroes muertos en los altares de la ciencia" que merecían el reconocimiento de la opinión pública, en lugar de los militares que habían propiciado la larga guerra civil (Zamora, 1901: 123). En los ejercicios literarios se propagó la idea de que gracias a la ENPCM se abrió la puerta a las mujeres para sumarse a los próceres científicos a través de la instrucción de las futuras generaciones que fomentarían el progreso de la nación. En este sentido, las profesoras normalistas se encargarían de que "la ciencia ya no [estuviera] entre aristócratas", sino que se extendiera entre todas las clases sociales mediante la instrucción científica de la mayor cantidad de infantes (Zamora, 1901: 124). Si el varón se adentraba a la ciencia bajo la reflexión teórica, los "descubrimientos" y la práctica profesional, la mujer se equiparaba a éste con la docencia al transmitir la vanguardia científica en el aula bajo las explicaciones románticas y positivas. Para ello, los libros de geografía y lecciones de cosas eran las armas de la profesora normalista, como lo era el estetoscopio, el teodolito o el mechero para los hombres.

Zamora reconoció que la tarea de las egresadas de la ENPCM en el futuro del Estado era vital, pues "el hombre [mantenía] una relación directa con las mujeres que le inculcaron las primeras ideas del bien o del mal, y si la mujer no se [instruía], estas últimas semillas [eran] las que [sembraría] y cuyo fruto [recaería] en la nación" (Zamora, 1901: 124). Las "primeras ideas" no sólo eran buenas o malas en términos morales o de civilidad, pues al inicio del siglo xx la ciencia formaba parte sustancial de la formación de un criterio basado en la razón y la 
experimentación, mientras que la superstición se asentaba en mitos y creencias populares. Lo anterior fue central en las políticas modernizadoras del gobierno porfiriano en el terreno médico, terapéutico, agrícola, higiénico, minero, silvícola y tecnológico. Ámbitos con amplia repercusión económica.

Por último, Zamora enfatizó que la formación educativa de los futuros científicos no iniciaba en las escuelas profesionales, sino en la escuela primaria. En ésta, la mujer ostentaba un papel protagónico al inculcar las simientes de la mineralogía, geografía, historia natural y, por supuesto, geología. De esta manera, el niño en el futuro penetraría en las entrañas de la tierra, para arrancar "sus ricos tesoros de oro, plata y platino, los tres preciosos metales tan codiciados por el hombre" que representaban la bonanza de México (Zamora, 1901: 127). Aunque esta conferencia no abordó una disciplina en particular, es evidente que en la ENPCM se enfatizaba el provecho de la ciencia en términos sociales y del Estado, así como la necesidad de que las mujeres incorporaran a la ciencia en su vida para ser agentes útiles a la nación. ¡Y qué mejor manera de serlo que como docente de la infancia!

\section{Los estudios planetarios}

Las cátedras de contenidos geográficos y naturalistas dotaron a las alumnas de la ENPCM de las nociones geológicas necesarias para explicar el origen del planeta, las características de su superficie y la posible estructura mineralógica subterránea. Un ejemplo de las explicaciones geológicas en boga que aprendían las estudiantes se encuentra en la conferencia de 1891 impartida por Cristina Arce cuyo título es "Forma y principales movimientos de la Tierra". En ésta se exponía que la geología enseñaba que el planeta, a pesar de ser "tan macizo, no [era] sino un juguete liviano en el éter, balanceado y mecido de mil maneras por las poderosas fuerzas cósmicas". Una de las hipótesis sobre la esfericidad de los planetas, satélites y soles explicaba que los movimientos de rotación y traslación habían moldeado la materia incandescente que originó todos los cuerpos cósmicos. Las fuerzas internas habían achatado la esfera terrestre en los polos, "siendo la causa de ese aplanamiento su rotación en torno del eje, en su origen fluido e incandescente" (Arce, 1891: 7). La explicación científica desprovista de los parámetros creacionistas de origen bíblico salta a la vista en la conferencia de Arce, aunque la narración empleó alegorías románticas para adentrar a la audiencia en un tema complejo que requería de ciertos conocimientos especializados.

Años más tarde, la alumna Ana María Castro señaló en "Origen de la Tierra" (1896) que varios geólogos especulaban que en la conformación inicial del universo sólo existía "la noche del vacío y de la nada. Era la espantosa calma del no ser, [...] en el seno de las tinieblas se levantó una fuerza poderosa y los factores físicos y químicos" dotaron a la materia cósmica de núcleos que originaron los sistemas solares y cuerpos planetarios (Castro, 1896: 162). 
Como en la conferencia de Arce, la expositora mezclaba datos positivos con el romanticismo científico para explicar la creación del universo y de la Tierra, pues apelaba a factores físicoquímicos para manifestar la constitución geológica de los cuerpos celestes bajo una narrativa amena y sencilla, desprovista de elementos teológicos, aunque la semejanza de ciertas alegorías con éstos es patente. También resalta el énfasis en un proceso geológico de larga duración, el cual había conducido a la Tierra:

\begin{abstract}
del estado de nebulosa formada de la atmósfera del Sol a la de una masa de materias incandescentes y en fusión, pero si se [comprendía] que con el transcurso de los siglos el globo terrestre, envuelto en multitud de gases, fue perdiendo su calor, su parte exterior empezó a solidificar y a medida que el grado de su temperatura se hacía menos elevado, su solidez era mayor y su atmósfera era cada vez menos vaporosa. La forma tomó pues, la forma de un elipsoide, lo que fue enunciado por Newton y comprobado después por observaciones [...] La corteza solidificada ya, pero todavía débil para resistir el potente empuje de las materias en fusión que de su interior tendían a escaparse y de los gases que se producían por la presencia de los metales que en estado libre [existían] en su centro, cedió al fin, y por varias partes les dio salida. Combinándose con el oxígeno que [constituyeron] la primera materia litológica del planeta, en la que [predominaban] el potasio, calcio, magnesio y aluminio (Castro, 1896: 164).
\end{abstract}

Las palabras de la conferencista dejan ver los temas aprendidos en clase que requerían de un ejercicio de abstracción para comprender la dinámica geológica producida en millones de años a partir de algunas evidencias científicas. A la par, las alumnas asimilaban algunos conceptos especializados para reforzar tal abstracción, como los referentes a la dinámica de fluidos, astronomía y metalurgia, por mencionar algunos. Es patente el esfuerzo de Castro por explicar al público un tema tan complejo mediante una narrativa simple y adecuada a personas ajenas a la práctica geológica, como sus futuros pupilos.

Castro describió las eras geológicas (precámbrica, paleozoica, mesozoica y cenozoica) como un proceso de larga duración, que se comprendían a través de los datos geológicos, ya que "el paso de estas edades [marcaba] inmensos espacios de tiempo que la ciencia no [podía] precisar con exactitud y que sólo [se concebía] por los fósiles que [caracterizaban] cada uno de los terrenos que [constituían]" (Castro, 1896: 167). Las evidencias de la sucesión de seres vivos a través de las eras geológicas formaron parte del bagaje científico que aprendían las alumnas de la ENPCM, que se reforzaba con las lecciones de zoología y botánica. No obstante, el registro fósil era discontinuo y en México la paleontología estaba inmersa en un proceso de emergencia disciplinar que aún no concluía. Por lo cual, la mención a ésta en el aula fomentó el interés entre los niños. 
Ana María Castro concluyó señalando que "aunque la ciencia no [fijaba] asertivamente la época en que el hombre hizo su aparición sobre la Tierra, [comprendía] por sus observaciones que fue en el periodo cuaternario, época adecuada a sus necesidades" (Castro, 1896: 170). De nuevo se apeló a la ciencia como la mejor explicación sobre el origen del ser humano, dejando de lado las elucidaciones religiosas, como era recurrente en la época, aunque se señalaba las limitaciones de las evidencias para establecer una fecha concreta. Éste es un ejemplo del tipo de explicación laica, positiva y fundamentada en demostraciones materiales que las profesoras normalistas popularizarían en la escuela.

A principios de siglo xx, Berta Vergara retomó el tema expuesto por las alumnas anteriores en "El desenvolvimiento de la Tierra en sus diversas edades" (1902), al manifestar que la geología estaba unida a la astronomía en el esclarecimiento de los procesos llevados a cabo en el seno del planeta millones de años antes de la vida humana. Por un lado, los científicos recurrían a "los rastros que en la Tierra [había] dejado impresa cada etapa" mediante los estratos geológicos y los fósiles, mientras que con el telescopio se observaba la faz de otros planetas que presentaban "aspectos que la Tierra debió tener en la época correspondiente" (Vergara, 1902: 87). La historia natural aportaba elementos para desentrañar la vida de las especies de tiempos prehistóricos bajo la interpretación darwiniana de la "lucha por la existencia". Vergara describió una posible escena sobre seres prehistóricos que habitaban los mares, como:

el ictiosauro de cuello corto, mandíbulas enormes, cuya abertura pasaba de un metro, teniendo dos filas de 180 dientes, cuya columna vertebral compuesta de 100 vértebras le permitía hacer los más flexibles movimientos con su cola larga y sus ojos que nacían a raíz de la cabeza de un pie de anchura. Nadaba negligentemente hacia la mitad del río, cuando rápido como el huracán se lanzó en su contra un colosal plesiosauro de pequeña cabeza y largo cuello. La primera embestida fue terrible, pues el agua quedó machada de sangre en un radio considerable. Después, durante algunos segundos, no [se pudo] distinguir más que una masa confusa en medio del remolino coronado de espuma rojiza que formaban los animales al abatirse. Por último, una nueva embestida del plesiosauro, el ictiosauro, en rápida evolución presentaba el frente a su contrario y abriendo desmesuradamente los maxilares tomó a éste por el cuello y hasta mis oídos llegó el crujir de huesos triturados y el chapoteo de las olas teñidas de rojo vivo. Después, nada. Las aguas siguieron tranquilas y el silencio volvió a reinar (Vergara, 1902: 90).

La narración de Vergara sobre la lucha por la sobrevivencia de ambos animales era común en la época en libros, revistas y conferencias dedicados a divulgar la paleontología entre un público amplio (Vega y Ortega, 2012: 336-353). Es patente la profundidad del estudio que la conferencista requería para expresar a la audiencia los pormenores de la vida animal de tiempos pasados. También se observa el empleo de conceptos de evolución que, aunque 
someros, reforzaban la explicación geológica (laica y positiva) del origen de la Tierra al introducir el devenir de seres vivos ya extintos.

En 1893 Luz García Sánchez presentó la conferencia sobre "La Tierra y sus principales aspectos", enfatizando los accidentes de la superficie. En este trabajo quedó clara la unión entre geografía y geología, pues la primera estudiaba la amplitud, localización y forma de las montañas, mientras que la segunda analizaba su composición mineralógica y origen. La alumna invitó al público a observar la orografía mexicana y deleitarse en los paseos con las "majestuosas sinuosidades" del valle de México, como las "eminencias y cumbres" del Popocatépetl, Iztaccíhuatl, Ajusco y demás serranías (García Sánchez, 1893: 153). Esta vez se nota el recurso de los paseos como estrategia para adentrar a los individuos en la geología, pues se esperaba que el paseante, mediante la observación, se formulara preguntas sobre las bellezas naturales que trataría de responder en libros, conferencias, revistas y cátedras. Una estrategia que es probable que las profesoras normalistas emplearan en la escuela primaria para explicar la conformación territorial de los alrededores de cada una de ellas.

García Sánchez explicó que, aunque el ser humano desconocía la composición terrestre más allá de cinco kilómetros de profundidad, los geólogos suponían que la corteza planetaria medía hasta 100 kilómetros hasta llegar al centro de la Tierra. La hipótesis geológica consideraba que éste se encontraba "en el mismo estado en que se hallaba todo el planeta en su origen". Una de las evidencias contundentes eran las excavaciones mineras que permitían al ser humano descender hacia las entrañas del orbe. Los mineros percibían que por cada 30 metros de profundidad la temperatura aumentaba un grado centígrado, resultando que a una profundidad de 100 kilómetros había 3000 grados. Una "temperatura suficiente para fundir todos los cuerpos [...] siendo esto una prueba irrecusable de que el centro de la tierra se [encontraba] en plena fusión" (García Sánchez, 1893: 156). Los diferentes ejercicios literarios estuvieron encaminados a enseñar a las expositoras a emplear las evidencias científicas como argumentos para la instrucción de primeras letras. Para ello, requerían de una sólida formación positiva en las cátedras más una práctica romántica en términos narrativos que auxiliaba a la comprensión de los datos científicos acorde con la edad de los infantes.

La conferencista concluía que la actividad geológica de la Tierra se mantenía a pesar del proceso de enfriamiento de los últimos millones de años, ya que ésta modificaba "todavía la corteza sólida del globo, ya bruscamente, y de una manera lenta y continuada [había] embellecido la Tierra” con grutas, volcanes, cañadas, fiordos y peñascos (García Sánchez, 1893: 157). La mencionada actividad geológica como fuerza escultora del relieve terrestre recordó a la audiencia la magnitud de algunos fenómenos como los sismos y erupciones volcánicas, a la vez que los millones de años acumulados que habían formado las cumbres del valle de México. Una disquisición, de nuevo, alejada del creacionismo religioso. 
La explicación del origen y características internas de la Tierra abrevaron de la geología romántica y positiva que, en conjunto, brindó a las conferencistas de elementos para adentrar al público en esta ciencia, como ensayo de las tareas que desempeñarían ante un grupo de infantes. Éstas se propusieron mostrar el vínculo de los conceptos geológicos con los astronómicos, naturalistas y geográficos aprendidos en diversas cátedras y reforzados en los libros de la biblioteca de la ENPCM.

\section{Los estudios sísmicos}

La sismicidad fue uno de los fenómenos que la geología estudió durante todo el siglo XIX por las evidencias que presentaba para discusiones como el origen de la Tierra, la evolución de los seres vivos y la constitución interna del planeta. En el caso de la ciudad de México, los movimientos telúricos fueron del interés de los científicos porfirianos por la amplia cantidad registrada en el valle de México. Tal vez por esta razón, Paula Vogel expuso al público los "Movimientos sísmicos" (1901). En esta conferencia, la alumna preguntó a la audiencia "¿se [había dado] una explicación clara y precisa respecto a la causa de estos movimientos?". La respuesta fue negativa, pues las causas eran diversas. Por un lado, se encontraban los sismos producidos por volcanes, como el caso del Popocatépetl; por otro lado, existía una capa de fluidos gaseosos y líquidos bajo la superficie terrestre que era el probable motor de la mayoría de los movimientos subterráneos. Ésta ejercía presión interna que empujaba lentamente la corteza terrestre hasta encontrar un respiradero, gracias a los sismos. De lo contrario "estallaría el planeta, como [reventaba] el receptáculo que [contenía] aire comprimido cuando [aumentaba] la presión" (Vogel, 1901: 8-9). El tema de los terremotos fue constante en las revistas científicas mexicanas, por los constantes movimientos sufridos en varias regiones. Éstos eran explicados de forma popular desde la perspectiva religiosa o sobrenatural que ocasionaban más desgracias que el propio sismo. Por ello, las profesoras normalistas eran las encargadas de popularizar las explicaciones geológicas a los niños y niñas para que en el futuro transmitieran los valores científicos a su familia. Los intelectuales porfirianos que apoyaban a la ENPCM confiaban en que después de varias generaciones de infantes instruidos en la ciencia se diluiría la superstición y el miedo a los sismos entre el pueblo.

Vogel señaló diversos aparatos que los ingenieros habían concebido para estudiar los temblores, en especial, la medición de la intensidad, duración y foco. Con tales datos se confeccionaban escalas que aportaban su caracterización, desde los imperceptibles hasta los devastadores. Tales aparatos se empleaban en observatorios e instituciones científicas, por ejemplo dos tipos de sismógrafo inventados por John Milne (1850-1913) y Luigi Palmieri (1807-1896). Vogel explicó que este último funcionaba mediante una corriente eléctrica que ponía en movimiento un reloj al inicio del temblor "y además [detenía] el movimiento de 
otro reloj que estaba andando. El resorte en espiral en contacto con el mercurio contenido en unos tubos en $U$ [expresaba] si el movimiento [era] trepidatorio" u oscilatorio. Sin embargo, cualquier persona podía construir un sismógrafo sencillo al poner una cadena fija en el techo que sostuviera una bala de cañón que en la parte inferior tuviera una punta de metal sumergida ligeramente en un plato de madera lleno de arena para dibujar el movimiento (Vogel, 1901: 15). La reseña de los modernos instrumentos empleados por los ingenieros o cualquier individuo da pie a conocer la materialidad científica de la época que se vivía en las instituciones porfirianas, a la vez que permite escudriñar la instrumentación amateur en el hogar, de la cual es posible que varias mujeres estuvieran interesadas.

Los estudios sísmicos pudieron ser de provecho para el público asistente a los ejercicios literarios para comprenderlos en su vida diaria y despojarse del aura sobrenatural. A la par, a los grupos de científicos les interesaba trasmitir las explicaciones científicas entre los alumnos de las escuelas primarias para despejar las dudas y la superstición sobre el movimiento de la corteza terrestre que, en ocasiones, se aprendían en el hogar. De nuevo, las alumnas normalistas serían las propagadoras del conocimiento geológico y sembrarían la semilla de la ciencia en cada infante.

\section{Los estudios sobre las bellezas geológicas}

En el ámbito de las peculiaridades geológicas, las alumnas de la ENPCM emplearon a fondo la vertiente romántica de la geología, pues la exaltación de la belleza y magnitud de las formaciones rocosas, junto con la imaginación de los observadores, conformaron el sustrato de este tipo de narrativa cercana a todo público. Este tipo de descripción estuvo encaminada a instruir de forma amena y entretener a las elites en las investigaciones positivas que desempeñaban los ingenieros y naturalistas. Entre las bellezas geológicas resaltaron volcanes, grutas, peñascos, cavernas y géiseres que atraían de forma continua a excursionistas en todo el mundo. Es probable que, por tal razón, la alumna Concepción Patiño presentara la conferencia titulada "La gruta de Cacahuamilpa" (1895). Al inicio, la conferencista resaltó que el estudio de la geología, "despojado de la aridez que [caracterizaba] al de las ciencias abstractas, [ofrecía] el mayor atractivo, aunando lo útil a lo agradable [...] para examinar, ante todo, las partes sólidas del globo [...] y escudriñar la naturaleza del interior de la Tierra" (Patiño, 1895: 128). La alumna diferenciaba la geología positiva, como la práctica masculina de recabar datos, efectuar "descubrimientos" y formular teorías, mientras que la geología romántica era empleada por hombres y mujeres como medio de instrucción y divulgación. Esta última fue tarea de las estudiantes.

La conferencista expresaba que mediante la geología se conocían las fuerzas planetarias que moldeaban el subsuelo para crear maravillas como Cacahuamilpa. Entre las fuerzas más 
poderosas estaban la acción del agua, volcanes y sismos. La primera parecía haber formado la impresionante gruta mexicana, gracias a la continua acción de dos ríos que nacían de esta montaña, se adentraban en la gruta y surgían al pie de ella. Una sencilla explicación basada en los contenidos de las cátedras geográficas. Patiño relató una excursión emprendida con su familia y amigos en los primeros meses para visitar la gruta. Para ello, el padre de familia compró luces de bengala, cohetes de luz, hachones y aparatos para producir luz de magnesio, así como víveres, ropa adecuada y otros objetos. Los excursionistas salieron de la ciudad de México a las 7 a.m. de la estación del tren Interoceánico hasta llegar a Jojutla, Morelos, a las 17 horas. De ahí se trasladaron en caballo hasta el pueblo de Cacahuamilpa, Guerrero, para pernoctar. A las 6 a.m. del día siguiente, el grupo recorrió cerca de dos kilómetros hasta la entrada de la caverna que en su mayor altura tenía 21 metros por 46 de ancho, formando un arco de basalto. La conferencista y el resto de paseantes penetraron en la gruta, acompañados de dos guías indígenas y otros quince que cargaban los objetos conseguidos en la capital y teas de ocote. La primera sala se conocía como del "Chivo Encantado" por una estalagmita que daba la apariencia de tal animal (Patiño, 1895: 134). Otras salas descritas por Patiño fueron "del Trono", "la Aurora", "el Panteón", "del Agua Bendita", "el Pedregal”, "el Muerto", "las Palmas" y "los Órganos". La conferencista llevó a cabo una descripción romántica y pormenorizada de cada sala al señalar las formaciones geológicas de mayor belleza, el posible origen de ellas, la impresión que causaba en el alma la soledad del mundo subterráneo, las conversaciones sostenidas entre los paseantes, entre muchos otros temas.

Una de las descripciones más interesantes sobre las salas fue la del estrecho salón conocido como "del Agua Bendita". Patiño resaltó que había una hermosa estalagmita que parecía una fuente de mármol en la que caía gota a gota una agua pura y cristalina que décadas antes había sido visitada por monseñor Ambrosio María Serrano y Rodríguez (18181875), primer obispo de Chilapa, quien bendijo el agua (Patiño, 1895: 136). La visita del obispo refiere la amplia concurrencia a la gruta de Cacahuamilpa por parte de la elite del estado de Guerrero que no se redujo a los científicos o amateurs, sino que los paseantes fueron mujeres, familias, miembros del clero, empresarios, comerciantes y hacendados, de los que aún se conoce poco como actores en la historia de la ciencia mexicana.

Después de casi cinco horas, los excursionistas emprendieron el regreso desde el salón de los "Órganos" que era el final del recorrido, pues más allá la gruta continuaba pero nadie se había atrevido a continuar. Tal salón había sido conocido por una excursión encabezada en 1883 por el presidente de la República, Porfirio Díaz, "quien a su vez había dejado atrás a las nueve excursiones que se habían hecho a la caverna" (Patiño, 1895: 138). Como se aprecia, el recorrido era largo y lleno de peligros, pero bien valía la pena conocer una de las maravillas geológicas de México. Es posible que algunas de las profesoras normalistas, afectas a los paseos y excursiones para conocer la naturaleza y el territorio del país, relataran a 
los alumnos sus impresiones científicas para explicar algunos temas e inculcar el amor a las ciencias desde sus tiernos años.

La conferencia de Concepción Patiño es el ejemplo más claro de la geología romántica como narración atractiva para un público amplio sin especialización en las ciencias de la Tierra. Esto como una estrategia de instrucción científica para los infantes de la escuela primaria que fue popular en los libros de texto y la prensa infantil.

\section{Los estudios sobre minerales}

La geología tuvo como base la amplia tradición de estudios mineralógicos encaminados a la explotación de los recursos del subsuelo en todo el orbe. Por ello, varios de los ingenieros de minas de Europa y América se desempeñaron como geólogos. Esta situación hizo que la geología guardara vínculos con la historia natural, al abordar el estudio del reino mineral. Dos conferencias versaron sobre este tema. La primera fue impartida en 1894 por Eloísa Álvarez y Gavarrón Ilamada "Propiedades principales y aplicaciones del carbón". La alumna iniciaba cuestionando a la audiencia si el ser humano "¿no [poseía] una brillante inteligencia para que [pudiera] razonar, percibir errores y aprovecharse además de los cuantiosos bienes regados por doquier para que los [utilizara]?” (Álvarez y Gavarrón, 1894: 147). Tal pregunta se basó en la visión utilitarista de la ciencia en la cual, los seres vivos, minerales y recursos ambientales estaban al servicio del ser humano bajo la explotación científico-técnica. Una visión positiva que se inculcaba a los infantes desde la escuela de primeras letras para afianzar a los futuros agentes del "progreso" nacional.

Álvarez y Gavarrón decía que el ser humano era poderoso porque era inteligente, ya que había "podido dominar sin más arma ofensiva que la inteligencia a todo ser viviente del globo terráqueo. Él [era] el soberano que [disponía] en lo absoluto de lo que [encontraba] a su paso, inventando medios adecuados para satisfacer sus diversas necesidades", muchos de los cuales requerían como fuente de energía al carbón (Álvarez y Gavarrón, 1894: 148). La cultura de cuño científico finisecular se basaba en la mencionada superioridad del ser humano frente al resto de especies gracias a la razón que efectuaba la gama de ciencias útiles. Éstas eran el motor del progreso en todos los países "civilizados" y, en el caso mexicano, habían transformado la faz del país gracias a la paz porfiriana, colmándolo de trenes, fábricas, puertos, puentes, tranvías y grandes edificios. La explotación minera se convirtió en la base del progreso mexicano que se reforzaría con las nuevas generaciones instruidas en la ciencia, tanto ingenieros como empresarios y mineros.

La conferencista explicaba la naturaleza del carbón mediante las partículas casi microscópicas, sólidas e insolubles en cualquier líquido, excepto en el hierro fundido, de un color variado, diversa densidad, "conductibilidad para el calor y la electricidad". La alumna contaba que 
en la metalurgia este mineral se empleaba por la capacidad reductora para extraer metales combinados con otros cuerpos y gracias a la energía que guardaba en tales partículas, el carbón proporcionaba comodidades para calentar los hogares y era la fuente motriz de la industria, las artes y las ciencias (Álvarez y Gavarrón, 1894: 149). Este mineral al final del siglo XIX se había erigido en símbolo del progreso, del movimiento de vehículos y adelanto en las comodidades hogareñas. La locomotora y los barcos hicieron posible que el ser humano llegara a todos los confines del planeta. Una nación civilizada, como México, requería del carbón y de ingenieros que lo explotaran de forma intensa en el futuro. Éstos se iniciarían en el medio científico desde la escuela de primeras letras.

La segunda conferencia sobre minerales fue de Dolores García, que expuso "El azufre y sus principales compuestos" (1898). De manera semejante a Álvarez y Gavarrón, la alumna explicaba que "el hombre por medio de sus investigaciones [conocía] las propiedades de todos los cuerpos para poder aplicarlas a varias artes que les [prestaba] inmensos beneficios" (García, 1898: 117). La confianza en la ciencia como vía para explotar los recursos naturales estaba difundida en la época en México, en especial en las escuelas profesionales, se transmitía a los niños a través de la escuela primaria, para lo cual las profesoras normalistas debían internalizar tal concepción del mundo en su paso por la ENPCM.

El azufre, como el carbón, era un mineral de amplio valor por los numerosos servicios que prestaba como sólido o líquido. La caracterización de éste por García en estado de pureza presentaba color amarillo limón, era insípido e inodoro, el frotamiento le daba un ligero olor parecido al ozono y presentaba la facultad de atraer los cuerpos ligeros. La conferencia expuso que el azufre se extraía de terrenos volcánicos llamados solfataras donde existía en estado nativo mezclado con materias terrosas. Entre las aplicaciones en la industria se encontraba la pólvora, los ácidos sulfuroso y sulfúrico, con los cuales se trataban varios metales (García, 1898: 119). De nueva cuenta, las alumnas normalistas se mostraron convencidas del papel de la ciencia en el progreso de las naciones en la explotación de recursos naturales que enriquecían al erario. Es de suponer que tal concepción se enseñaba en la escuela primaria por las profesoras que habían sido preparadas para ello en las cátedras científicas.

Es evidente la idea finisecular de que el progreso se evidenciaba en las naciones civilizadas a través del usufructo de los recursos naturales, como los mineros, que aportaban la energía necesaria para distanciar a los hombres "modernos" de lo "salvajes" mediante las comodidades de la vida "moderna". Así, los niños aprendían que el ser humano era el soberano del mundo gracias a la ciencia que transformaba a las sociedades y dominaba al resto de especies y los recursos ambientales. 


\section{Consideraciones finales}

La historia social de la ciencia permite comprender la participación de varios actores en el devenir de la gama de disciplinas científicas más allá de los grupos tradicionales, como los profesionistas (ingenieros, médicos y farmacéuticos). De esta manera, la participación femenina en tal devenir adquiere un valor histórico distinto al que ocupó décadas anteriores en la historiografía. En el caso de las conferencias científicas de las alumnas de la ENPCM, en especial las geológicas, es patente su valía como testimonio de su incursión en la ciencia mexicana con el objetivo de instruir a los infantes en la escuela primaria.

En efecto, la historia de la geología mexicana ha enfatizado el papel de los hombres en su devenir desde el siglo XVIII y ha dejado de lado la participación de las mujeres en diversos ámbitos más allá del medio académico. La iniciación de las conferencistas hizo posible que se adentraran en el saber positivo y romántico con el propósito de explicar los fenómenos geológicos a los niños. Para ello, se empleó la narrativa romántica unida a la explicación positiva acorde con la edad de los alumnos. Cabe recordar que el propósito de las conferencias científicas era que las jovencitas conocieran la ciencia mexicana y mundial para luego trasladarla al aula mediante su exposición en cada clase y el empleo de libros de texto de geografía y lecciones de cosas, así como láminas, paseos, colecciones de objetos, entre otras cuestiones.

Al final del siglo XIX, los ingenieros incidieron en algunos aspectos de la instrucción primaria al convencer al gobierno de la necesidad de crear una representación geológica del país adecuada a los infantes. Sólo así se dotaría a los niños de una concepción utilitaria de la ciencia en cuanto a la explotación de los recursos mineros. Así, las profesoras se sujetarían a los cánones de la ciencia positiva, a la par que aderezaban las explicaciones con la retórica romántica. También es claro el aprecio de las conferencistas por la geología como motor de la modernidad tecnológica ejemplificada en el transporte, la industria y los recursos naturales que se explotaban.

Es evidente que en las conferencias geológicas se concibe al ser humano, en especial al varón, como el único ser capaz de explotar los recursos naturales, dominar la flora y fauna, colonizar el planeta y comprender el devenir del globo terráqueo. Todo ello a través de la ciencia y la tecnología. Tal concepción se basaba en la instrucción científica a todos niveles, iniciando por primeras letras, pues abarcaba a mayor número de individuos de ambos sexos, mientras que la educación superior restringida a las clases media y alta de las ciudades.

La publicación de los trece tomos de las conferencias científicas por parte de la Secretaría de Fomento fue un signo del apoyo del régimen porfiriano hacia la profesionalización de las mujeres en el área educativa y la confianza de las profesoras en el proceso de incluir a la ciencia en la educación elemental para "crear" ciudadanos modernos. En efecto, se esperaba 
que los niños en el futuro se convirtieran en las nuevas generaciones de profesionistas que continuarían el progreso material de México.

Es notorio que las jovencitas en las conferencias se adentraron a la práctica científica, hasta entonces reservada a los varones, y sirvieron como ensayo oral de las exposiciones que llevarían a cabo ante sus futuros pupilos de la escuela primaria. A pesar de que las conferencias analizadas muestran la presencia de la geología en las cátedras geográficas y naturalistas de la ENPCM, se aprecia que las alumnas aprendían a relacionar dicha ciencia con otras disciplinas impartidas en la institución, como química, geografía, astronomía, mineralogía y paleontología, que ayudaban a las ponentes a exponer de mejor manera el tema elegido.

Las estrategias de la geología romántica dotaron a las alumnas de elementos para "aligerar" las explicaciones teóricas y fisicoquímicas sobre el origen de la Tierra, los movimientos telúricos y las eras geológicas, que debían explicar a menores de edad. La conferencia con mayor tinte romántico reseñó un viaje a la gruta de Cacahuamilpa, pues sin dejar de lado las explicaciones positivas de su posible formación, la ponente enfatizó la importancia de contemplar las bellezas geológicas mexicanas, pues éstas despertaban una emoción nacionalista por el territorio. Es probable que en las cátedras de la ENPCM se enseñara a las alumnas a apelar al sentimiento patrio como inicio de una explicación científica entre los niños, pues de ésta manera la atención de los pupilos se mantenía constante (Vega y Ortega, 2010: 2843). Mientras que la geología positiva estuvo presente en las explicaciones, datos cuantitativos y teorías sobre ciertos fenómenos planetarios. Con ello, las profesoras Ilevarían a los alumnos el conocimiento de vanguardia. La unión de ambas perspectivas científicas fue constante en la instrucción primaria como se aprecia en revistas, manuales, folletos y libros de texto dirigidos al público infantil.

Por último, aún hace falta comprender el funcionamiento de las cátedras científicas de la ENPCM, así como las vías en que las egresadas propagaron el saber científico en el aula e incluso en otros medios, como manuales y revistas.

\section{Fuentes}

Aguirre, María Esther (2010), "La Geografía emigra a la escuela. Apuntes sobre la configuración de un campo disciplinar. Siglo xix (1825-1898)”, en Luz Elena Galván y Lucía Martínez (coords.), Las disciplinas escolares y sus libros, México, CIESAS-Universidad Autónoma del Estado de Morelos-Juan Pablos Editor, pp. 251-276.

Alvarado, Lourdes (1999), "La propuesta educativa femenina del gobierno republicano, 1867", en Patricia Galeana (coord.), La definición del Estado mexicano 1857-1867, México, Archivo General de la Nación, pp. 407-422. 
Alvarado, Lourdes (2008), "De Escuela Secundaria para Señoritas a Normal de Profesoras, 1867-1890", en Luz Elena Galván y Oresta López (coords.), Entre imaginarios y utopías: historias de maestras, México, CIESAS-UnAM-El Colegio de San Luis, pp. 105-126.

Álvarez y Gavarrón, Eloisa (1894), "Propiedades principales y aplicaciones del carbón", en Conferencias científicas de las alumnas de la Escuela Normal para Profesoras en el período del 3 de junio al 29 de julio de 1893, México, Secretaría de Fomento, pp. 147-158.

Arce, Cristina (1891), "Forma y principales movimientos de la Tierra", en Conferencias científicas de las alumnas de la Escuela Normal para Profesoras en el período del 6 de junio al 25 de julio de 1891, México, Tipografía de Aguilar e Hijos, pp. 7-14.

Azuela, Luz Fernanda (1994), "Las ciencias de la tierra en el Porfiriato", en María Luisa Rodríguez Sala y Omar Moncada (coords.), Enfoques multidisciplinarios de la cultura científico-técnica en México, México, UnAM, pp. 73-80.

(2011), "La emergencia de la geología en el horizonte disciplinario del siglo XIX", en Jorge Bartolucci (coord.), La saga de la ciencia mexicana. Estudios sociales de sus comunidades: siglos XVIII al XX, México, UNAM, pp. 55-78.

y Rodrigo Vega y Ortega (2011), "La ciudad de México como capital científica de la nación (1760-1910)", en Celina Lértora (coord.), Geografía e Historia Natural: Hacia una historia comparada. Estudio a través de Argentina, México, Costa Rica y Paraguay, vol. 4, Buenos Aires, Fundación para el Estudio del Pensamiento Argentino e Iberoamericano, pp. 51-90.

Castro, Ana María (1896), "Origen de la Tierra", en Conferencias científicas de las alumnas de la Escuela Normal para Profesoras en el período del $1^{\circ}$ de junio al 27 de julio de 1895, México, Secretaría de Fomento, pp. 161-171.

Galván, Luz Elena (2008), "Memoria escrita de maestras decimonónicas", en Luz Elena Galván y Oresta López (coords.), Entre imaginarios y utopías: historias de maestras, México, CIESAS-UNAM-El Colegio de San Luis, pp. 153-190.

García, Dolores (1898), "El azufre y sus principales compuestos", en Conferencias científicas de las alumnas de la Escuela Normal para Profesoras en el período del 5 de junio al 31 de julio de 1897, México, Secretaría de Fomento, pp. 117-123.

García Alcaraz, María Guadalupe (2008), "Las maestras tapatías: celibato y disciplina, 1867-1910", en Luz Elena Galván y Oresta López (coords.), Entre imaginarios y utopías: historias de maestras, México, CIESAS-UNAM-El Colegio de San Luis, pp. 127-152.

García Sánchez, Luz (1893), "La tierra y sus principales aspectos", en Conferencias científicas para las alumnas de la Escuela Normal para Profesoras en el período de 4 de junio a 30 de julio de 1892, México, Litografía y Tipografía de Montauriol, pp. 149-162.

Lionetti, Lucía y Alicia Civera (2010), "Temas, problemas y nuevos desafíos de la Historia Social de la Educación", Cuadernos Interculturales, vol. 8, núm. 14, pp. 15-19.

López, Oresta (2003), "Currículum sexuado y poder: miradas a la educación liberal diferenciada para hombres y mujeres durante la segunda mitad del siglo xIX en México", Relaciones. Estudios de Historia y Sociedad, vol. 29, núm. 113, pp. 33-68.

Patiño, Concepción (1895), "La gruta de Cacahuamilpa", en Conferencias científicas de las alumnas de la Escuela Normal para Profesoras en el período del 2 de junio al 28 de julio de 1894, México, Secretaría de Fomento, pp. 127-140.

Tanck, Dorothy (1976), "Historia social de la educación: un campo por explorar. El caso de la educación primaria en la ciudad de México, 1786-1836", Revista del Centro de Estudios Educativos, vol. 6, núm. 2. pp. 39-54.

Vaccarezza, Leonardo (2009), "Estudios de cultura científica en América Latina", Redes. Estudios Sociales de la Ciencia, vol. 15, núm. 30, pp. 75-103. 
Vega y Ortega, Rodrigo (2010), "La representación de Michoacán en los discursos geográfico y naturalista de tres revistas científicas de México, 1869-1910", Graffylia. Revista de la Facultad de Filosofía, vol. 7, núm. 11-12, pp. 28-43.

(2011), "Desde la margen del Bravo, hasta el valle donde se alza el Soconusco elevado: la Geografía en las revistas para niños (la década de 1870)", Antíteses, vol. 4, núm. 7, pp. 247-266.

(2012), "Los reinos de la naturaleza en la prensa infantil de México, 1870-1878", Revista Brasileira de História da Ciência, vol. 5, núm. 2, pp. 336-353.

(2013), "Instrucción, utilidad, especulación y recreación geológicas en las revistas de la ciudad de México, 1840-1861", Trashumante. Revista Americana de Historia Social, núm. 2, pp. 56-79.

Vergara, Berta (1902), "El desenvolvimiento de la Tierra en sus diversas edades", Conferencias científicas de las alumnas de la Escuela Normal para Profesoras en el período del $1^{\circ}$ de junio al 27 de julio de 1901, México, Secretaría de Fomento, pp. 85-94.

Vogel, Paula (1901), "Movimientos sísmicos", en Conferencias científicas de las alumnas de la Escuela Normal para Profesoras en el período del 3 de junio al 29 de julio de 1899, México, Secretaría de Fomento, pp. 7-15.

VV. AA, (1891), "Art. 88 del reglamento: ejercicios literarios", en Conferencias científicas de las alumnas de la Escuela Normal para Profesoras en el período del 6 de junio al 25 de julio de 1891, México, Tipografía de Aguilar e Hijos, pp. 3-5.

(1895), "Introducción", en Conferencias científicas de las alumnas de la Escuela Normal para Profesoras en el período del 2 de junio al 28 de julio de 1894, México, Secretaría de Fomento, pp. 3-4

(1897), "Introducción", en Conferencias científicas de las alumnas de la Escuela Normal para Profesoras en el período del 6 de junio al 25 de julio de 1896, México, Secretaría de Fomento, pp. 3-5.

(1901), "Conferencias científicas", en Conferencias científicas de las alumnas de la Escuela Normal para profesoras en el período del 3 de junio al 29 de julio de 1899, México, Secretaría de Fomento, pp. 3-6.

Zamora, Angelina (1901), "Amor a la ciencia", en Conferencias científicas de las alumnas de la Escuela Normal para Profesoras en el período del 3 de junio al 29 de julio de 1899, México, Secretaría de Fomento, pp. 121-129, [documento pdf disponible en: <http://cdigital.dgb.uanl.mx/ la/1080019496/1080019496_12.pdf; (consulta: 2/4/2015)].

Rodrico Veca y Orteca. Es profesor de los colegios de Historia y de Geografía doctor en Historia por la Facultad de Filosofía y Letras de la UNAM. Sus líneas de investigación son la historia de la ciencia y la historia ambiental de México en el siglo XIX. Publicaciones recientes: (2014), "Recorridos impresos por volcanes y grutas de México (1835-1861)", en Luz Fernanda Azuela y Rodrigo Vega y Ortega (coords.), Espacios y prácticas de la Geografía y la Historia Natural de México (1821-1940), México, Universidad Nacional Autónoma de México, pp. 61-86; (2014), "La vida pública del Museo Nacional de México a través de la prensa capitalina, 1825-1851", Tzintzun. Revista de Estudios Históricos, núm. 59, pp. 94-138.

Recibido: 30 de junio de 2014

Aceptado: 21 de septiembre de 2014 